\title{
Lignosulfonate and silica as precursors of advanced composites
}

\author{
Lukasz Klapiszewski, Magdalena Nowacka, Katarzyna Siwińska-Stefańska, Teofil Jesionowski* \\ Poznan University of Technology, Faculty of Chemical Technology, Institute of Chemical Technology and Engineering, \\ M. Sklodowskiej-Curie 2, 60-965 Poznan, Poland \\ * Corresponding author: e-mail: teofil.jesionowski@put.poznan.pl
}

\begin{abstract}
Advanced silica/lignosulfonate composites were obtained using magnesium lignosulfonate and silica precipitated in a polar medium. For comparative purposes analogous synthesis was performed using commercial silica Aerosil ${ }^{\circledR} 200$. Lignosulfonates are waste products of paper industry and their application in new multifunctional materials is of great economic interest. The composites obtained were subjected to thorough characterization by determination of their physicochemical, dispersive-morphological and electrokinetic properties. Their particle size distribution was measured, SEM images were taken, FT-IR analysis and colorimetric study were made, thermal and electrokinetic stabilities and parameters of porous structure were also determined. The results can be of interest in further application studies.
\end{abstract}

Keywords: Magnesium lignosulfonate; Silica; Silica/lignosulfonate composite; Physicochemical and structural properties.

\section{INTRODUCTION}

Increasing requirements concerning the standards of environment protection have prompted interest in the utilization of waste products and development of lowwaste or green industrial technologies. In this context design and production of new, relatively cheap composite materials based on products of natural origin such as lignin or lignosulfonate seems an important issue.

Thanks to a number of very attractive properties such as high hardness, chemical resistance, thermal stability, mechanical strength and well developed surface area, silica is the widest used inorganic material. It is used among others as a filler and carrier of organic compounds. Silica is synthesized by precipitation in a polar or nonpolar media ${ }^{1-3}$ or can be obtained in the so-called sol-gel method ${ }^{4,5}$.

Lignosulfonates (LS) are derived from lignin. They are the final products of black liquor processing in cellulose-paper industry. Black liquor is one of the waste products in the method of sulfite wood digestion to get cellulose. The lignosulfonate molecule shows unique properties as it contains the hydrophilic groups from sulfonic acid and hydrophobic groups from fragments of lignin. Lignosulfonates have been used e.g. as modifiers in water solutions or gels, as stabilizers of colloidal solutions, dispersing agents, plasticizers ${ }^{6}$, surfactants ${ }^{7}$, adhesives ${ }^{8}$, drilling emulsions ${ }^{9}$ or as admixtures of cement ${ }^{10}$. They are by far the most popular as dispersers facilitating deflocculation and dispersion of cement particles in concrete, as for these purposes about $50 \%$ of their global production is used ${ }^{10}$. Admixture of lignosulfonate to concrete mixtures improves their processing, decreases the amount of bound water and improves the mechanical performance of the products ${ }^{10,11}$.

Recently, much interest has been shown in the possibility of obtaining multifunctional composites of silica combined with natural polymers, including lignin and its derivatives. So far only a few methods have been proposed for the synthesis of silica/lignin materials ${ }^{12-16}$. The products obtained were characterized by large surface area, high thermal stability and high mechanical strength. Their potential applications include uses as functional biosorbents, polymer fillers and many others ${ }^{17}$. It is also possible to combine silica/lignin products with other compounds such as natural rubber ${ }^{18}$ or other polymers ${ }^{19}$.

The aim of this study was synthesis and characterization of advanced composites made from silica and lignosulfonate. The composites were subjected to thorough physicochemical, dispersive-morphological and electrokinetic analyses to indicate their possible applications.

\section{EXPERIMENTAL}

\section{Synthesis of silica in polar medium}

The silica precursor used in the study was precipitated in a polar medium as a result of the reaction between the water solution of sodium silicate (Vitrosilicon SA, Poland) and a 5\% solution of sulfuric acid (Chempur, Poland). A detailed description of this method of silica synthesis has been given earlier ${ }^{1}$. For comparative purposes also commercially available silica Aerosil ${ }^{\circledR} 200$ (Evonik Industries AG, Germany) was used. To activate the silica surface (both hydrated and commercial), its surface was modified with a 5 weight parts by mass of $N-2-($ aminoethyl)-3-aminopropyltrimethoxysilane (AEAPTES) (Sigma-Aldrich, Germany). A detailed description of the process of modification is given elsewhere ${ }^{20}$.

\section{Preparation of silica/lignosulfonate composites.}

Accurate amount of magnesium lignosulfonate in the form of dense liquid of $55 \%$ concentration (VIANPLAST 55, BIOTECH Lignosulfonate Handels-GesmbH, Austria) was diluted 10 times with water and then placed in a reactor in which it was vigorously stirred. After 15 minutes the reactor was charged with a proper amount of silica activated with aminosilane (Sigma-Aldrich, Germany). The contents were vigorously stirred for about $2 \mathrm{~h}$ at room temperature. The solvent was evaporated in a vacuum evaporator made by Büchi Labortechnik AG (Switzerland), and the final product was dried in a stationary drier at $105^{\circ} \mathrm{C}$ for about $24 \mathrm{~h}$ (Memmert, Germany). The samples obtained differed in the weight ratio of lignosulfonate to silica. 


\section{Methods of determination of physicochemical properties}

Particle size distribution of the composite samples was determined in the range 0.2-2000 $\mu \mathrm{m}$ (Mastersizer 2000, made by Malvern Instruments Ltd., UK) and their morphology was analyzed using in scanning electron microscope (SEM) images taken on a Zeiss EVO40 microscope (Germany). The electrokinetic stability of the composites was evaluated on the basis of zeta potential measurements on a Zetasizer Nano ZS (Malvern Instruments Ltd., UK). The measurements were performed in a $0.001 \mathrm{M}$ solution of $\mathrm{NaCl}$. Thermal analysis (TG) was performed on a Jupiter STA 449F3, made by Netzsch (Germany). The FT-IR spectra were recorded on an EQUINOX 55 spectrophotometer, made by Bruker (Germany), while the colorimetric analysis was made on a Specbos 4000 colorimeter (YETI Technische Instrumente $\mathrm{GmbH}$, Germany). The specific surface area based on BET (Brunauer-Emmett-Teller) equation as well as the total pore volume and the mean size of pores were determined using the BJH (Barrett-Joyner-Halenda) algorithm on the basis of measurements performed on an ASAP 2020 apparatus, Micromeritics Instrument Co. (USA).

\section{RESULTS AND DISCUSSION}

The particle distribution curves examined for silica/ lignosulfonate composites of different weight contributions of magnesium lignosulfonate per 100 parts by weight of $\mathrm{SiO}_{2}$ (hydrated or commercial) are similar, see Fig. 1a and b. The samples reveal the presence of primary particles of diameters close to $100 \mathrm{~nm}$, which show a tendency to formation of aggregates $(<1 \mu \mathrm{m})$ and agglomerates $(>1 \mu \mathrm{m})$. The samples show different dispersive-morphological properties.

As follows from the data presented in Table 1, with increasing content of lignosulfonate in the composite the number of larger particles increases. The tendency is evident for the composites based on hydrated as well as Aerosil ${ }^{\circledR} 200$ silica. This observation confirms the conclusions presented in the earlier works on the synthesis and characterization of silica/lignin composites ${ }^{\mathbf{1 2}-14}$. The presence of primary particles and secondary agglomerates is confirmed by SEM images (Fig. 2).

Figure 2a presents SEM image of magnesium lignosulfonate, while Fig. $2 b$ and $c$ show images of silica/ lignosulfonate composites obtained with the use of (a)

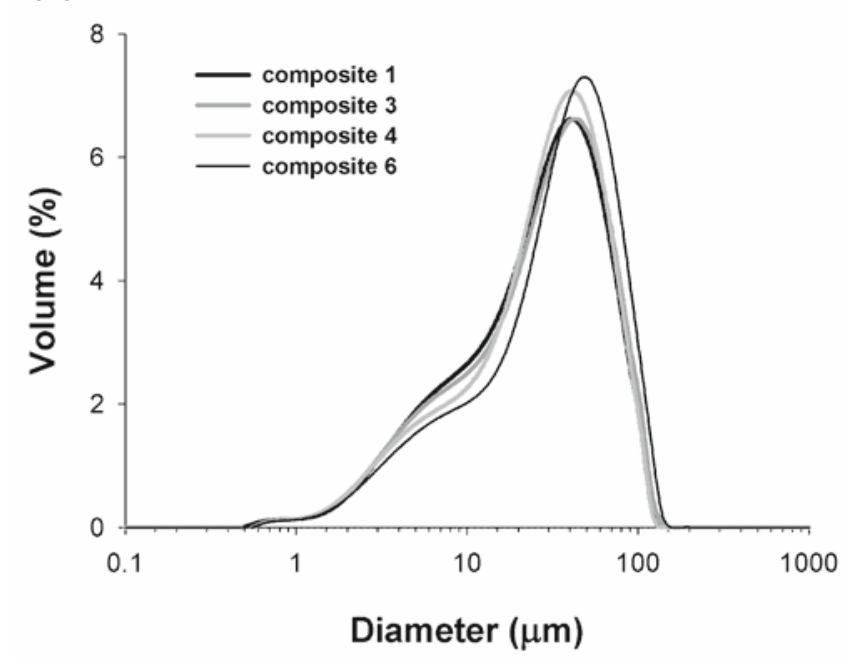

(b)

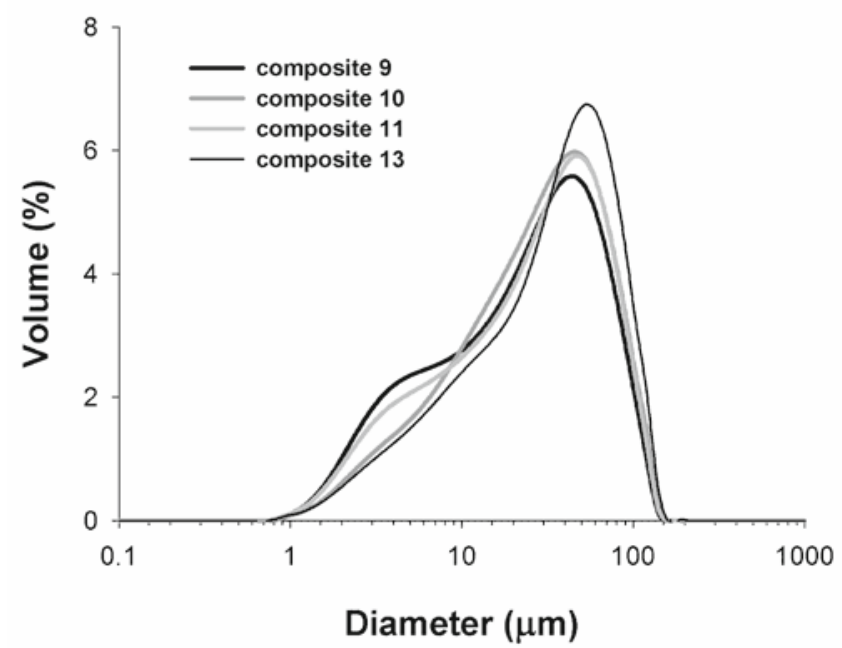

Figure 1. Particle size distributions (Mastersizer 2000) of silica/ lignosulfonate composites obtained on the basis of (a) hydrated silica and (b) Aerosil ${ }^{\circledR} 200$

hydrated and commercial (Aerosil ${ }^{\circledR} 200$ ) silicas. The products obtained, labelled as composites 4 and 11, and contained 20 weight parts of lignosulfonate per 100 weight parts of $\mathrm{SiO}_{2}$.

Figure 3 presents zeta potential as a function of $\mathrm{pH}$ measured for $\mathrm{SiO}_{2}$ /lignosulfonate composites.

The hydrated silica (Fig. 3a) and commercial silica (Fig. 3b) whose surfaces were functionalized with

Table 1. Dispersive properties of silica/lignosulfonate composites

\begin{tabular}{|c|c|c|c|c|c|c|}
\hline \multirow{2}{*}{$\begin{array}{l}\text { Composite } \\
\text { No. }\end{array}$} & \multirow{2}{*}{ Silica type } & \multirow{2}{*}{$\begin{array}{l}\text { Content of lignosulfonate in } \\
\text { relation to the modified silica } \\
\text { matrix (wt./wt.) }\end{array}$} & \multicolumn{4}{|c|}{ Particle diameter from Mastersizer $2000(\mu \mathrm{m})$} \\
\hline & & & $d(0.1)$ & $d(0.5)$ & $d(0.9)$ & $\mathrm{D}[4.3]$ \\
\hline 1 & \multirow{7}{*}{ hydrated silica } & 3 & 4.8 & 26.1 & 64.6 & 30.8 \\
\hline 2 & & 5 & 4.8 & 26.0 & 65.1 & 30.9 \\
\hline 3 & & 10 & 4.9 & 27.8 & 65.0 & 31.9 \\
\hline 4 & & 20 & 4.8 & 27.4 & 67.8 & 32.3 \\
\hline 5 & & 30 & 5.4 & 32.8 & 74.7 & 36.9 \\
\hline 6 & & 40 & 5.4 & 32.8 & 71.8 & 36.2 \\
\hline 7 & & 50 & 5.7 & 34.2 & 75.5 & 38.0 \\
\hline 8 & \multirow{7}{*}{$\begin{array}{c}\text { commercial silica } \\
\left(\text { Aerosil }{ }^{\circledR} 200\right)\end{array}$} & 3 & 3.5 & 23.1 & 67.7 & 30.0 \\
\hline 9 & & 5 & 3.9 & 25.7 & 71.1 & 32.2 \\
\hline 10 & & 10 & 3.4 & 25.0 & 75.1 & 32.7 \\
\hline 11 & & 20 & 4.0 & 25.9 & 75.5 & 33.2 \\
\hline 12 & & 30 & 5.1 & 26.8 & 72.5 & 33.5 \\
\hline 13 & & 40 & 5.2 & 29.5 & 73.9 & 35.3 \\
\hline 14 & & 50 & 5.5 & 32.7 & 79.7 & 38.1 \\
\hline
\end{tabular}




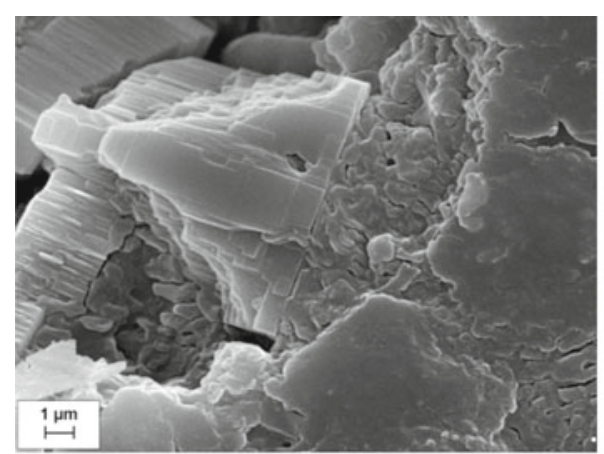

(a)

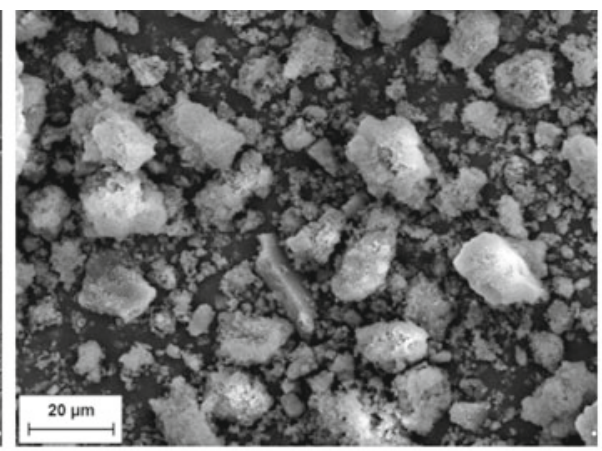

(b)

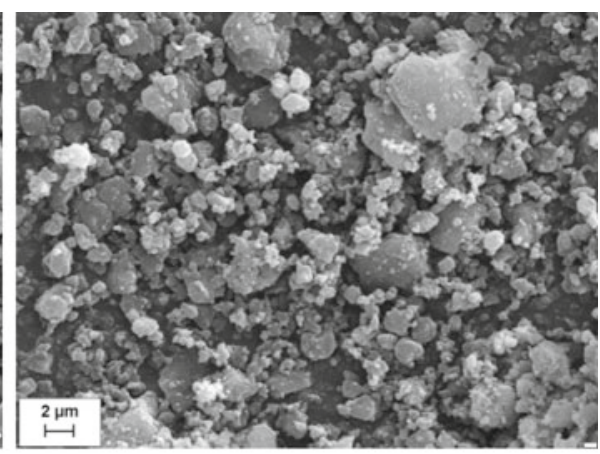

(c)

Figure 2. SEM images of (a) magnesium lignosulfonate (b) composite 4 and (c) composite 11

(a)

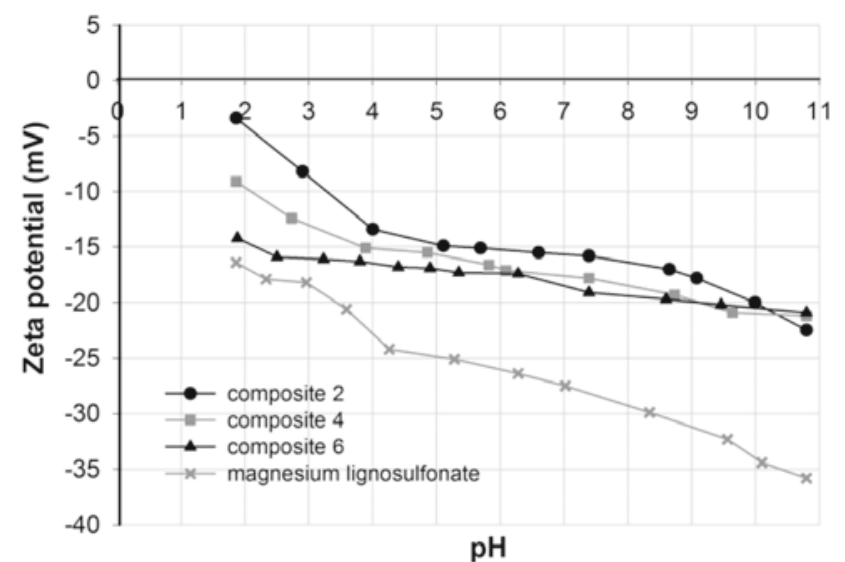

(b)

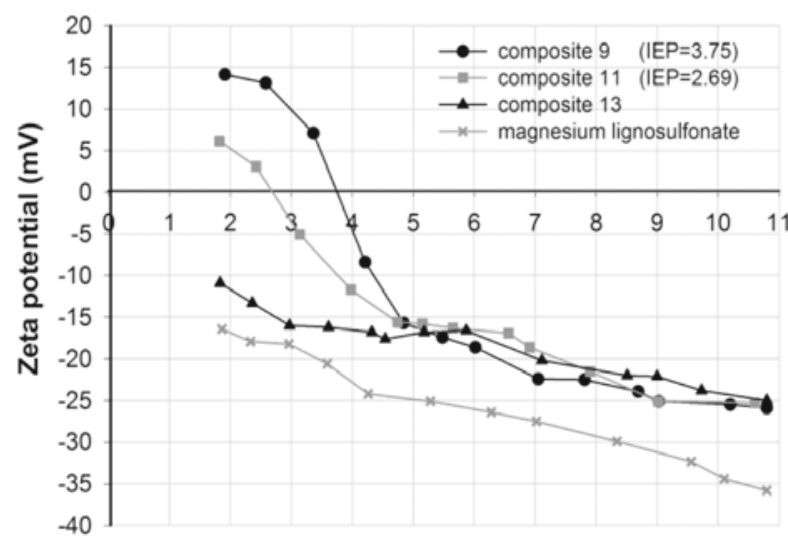

$\mathrm{pH}$

Figure 3. Zeta potential vs. $\mathrm{pH}$ of silica/lignosulfonate composites obtained on the basis of (a) hydrated silica and (b) Aerosil ${ }^{\circledR} 200$

aminosilane were used as inorganic support. The electrokinetic characterization of the initial silicas and the modified silica samples is described in an earlier paper ${ }^{\mathbf{1 4}}$. The zeta potential values measured for magnesium lignosulfonate varied in the range from -15 to $-35 \mathrm{mV}$. Electrokinetic properties of lignosulfonate have been described in detail in literature ${ }^{21,22}$. Both for hydrated and commercial (Aerosil ${ }^{\circledR} 200$ ) silicas, with increasing content of lignosulfonate in the composite, the zeta potential decreased, at a given $\mathrm{pH}$. The composites obtained showed high electrokinetic stability in almost all $\mathrm{pH}$ range analyzed (1.7-11). The electrokinetic curves obtained for composites 9 and 11 reach the isoelectric point (IEP) at $\mathrm{pH}$ of 3.75 and 2.69, respectively, which (a)
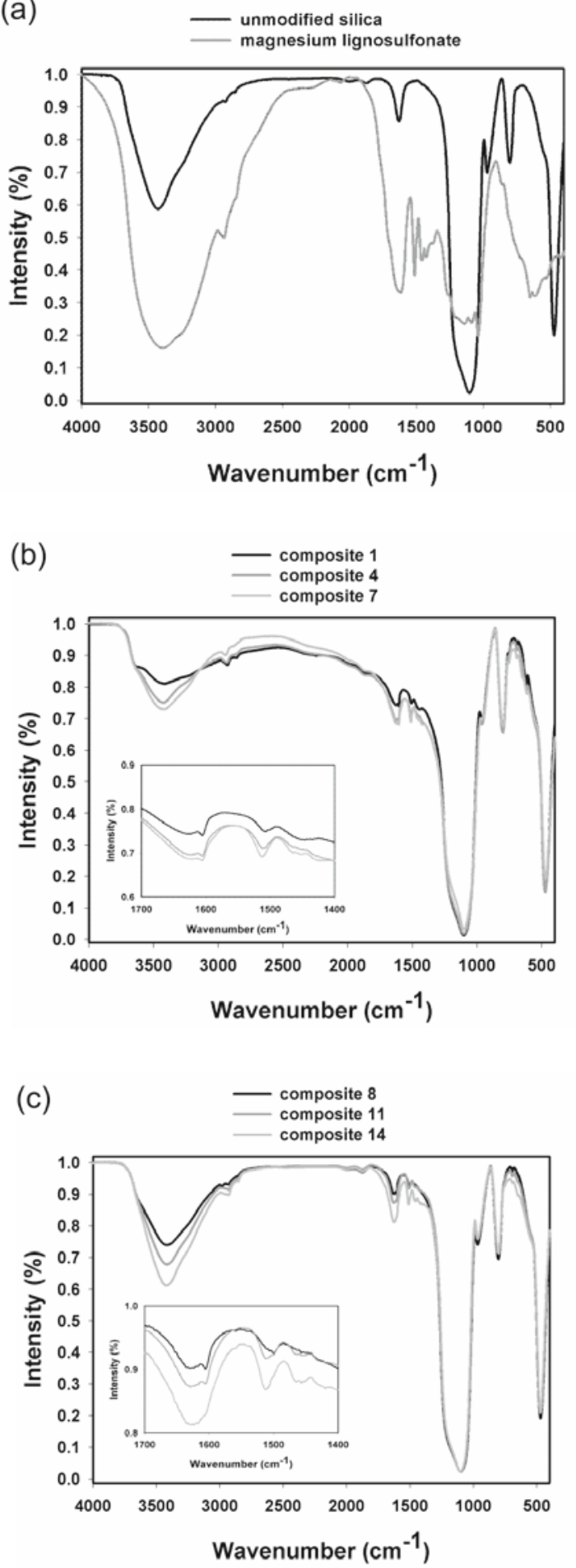

Figure 4. FT-IR spectra of precursors (a), final products obtained on the basis of hydrated silica (b), and Aerosil $^{\circledR} 200$ (c) 
is related to the presence of $-\mathrm{NH}_{2}$ groups coming from the modifier applied.

FT-IR analysis confirmed the practicality and effectiveness of combination of silica with lignosulfonate and permitted identification of the characteristic functional groups present in the precursor structures (Fig. 4a) or in final composites obtained with hydrated silica (Fig. 4b) and commercial silica - Aerosil ${ }^{\circledR} 200$ (Fig. 4c).

The characteristic bands in the spectra of initial reagents overlap the bands in the spectra of final products, which mean that the composites were successfully obtained in a controlled way. The spectrum of silica provides evidence that it contains the physically bound water. The broad band in the range of $3600-3200 \mathrm{~cm}^{-1}$ is assigned to the stretching vibrations of $\mathrm{O}-\mathrm{H}$ groups and the band at $1642 \mathrm{~cm}^{-1}$ corresponds to the bending vibrations of these groups. The bands at $1120 \mathrm{~cm}^{-1}$ and $817 \mathrm{~cm}^{-1}$ are assigned to the stretching vibrations of $\mathrm{Si}-\mathrm{O}-\mathrm{Si}$, the band at $960 \mathrm{~cm}^{-1}$ to the stretching vibrations of $\mathrm{Si}-\mathrm{OH}$ and the band at $466 \mathrm{~cm}^{-1}$ to the bending vibrations of $\mathrm{Si}-\mathrm{O}^{23-25}$ The FT-IR spectrum of lignosulfonate shows the characteristic bands assigned to the stretching vibrations of O-H groups (3600-3200 $\left.\mathrm{cm}^{-1}\right)$, stretching vibrations of $\mathrm{C}-\mathrm{H}$ groups $\left(2960-2835 \mathrm{~cm}^{-1}\right)$, and the stretching vibrations of ketone groups $\mathrm{C}=\mathrm{O}\left(1710-1550 \mathrm{~cm}^{-1}\right)$. The peaks at $1600 \mathrm{~cm}^{-1}, 1510 \mathrm{~cm}^{-1}$ and $1420 \mathrm{~cm}^{-1}$ correspond to the stretching vibrations of $\mathrm{C}-\mathrm{C}$ and $\mathrm{C}=\mathrm{C}$ bonds in the aromatic structure. Very important is the band with the maximum at $1036 \mathrm{~cm}^{-1}$, which is assigned to the symmetric stretching vibrations of $\mathrm{S}=\mathrm{O}$ from the $-\mathrm{SO}_{3}{ }^{-}$ groups contained in the lignosulfonate chain. Detailed analysis of the spectrum is in agreement with literature data $^{26,27}$. The proposed formation mechanism of silica/ magnesium lignosulfonate composite is shown in Fig. 5. As a result of the performed methodology followed by the creation of hydrogen bonds between the $-\mathrm{NH}_{2}$ groups of the surface modifier derived from silica and the hydroxyl groups present in the structure of lignin.

Additional evidence confirming the effective combination of reagents comes from colorimetric studies (Fig. 6a and b).

No significant differences were observed between the products obtained on the basis of two types of silica used. With an increase of the weight contribution of lignosulfonate in a composite, the lightness $L^{*}$ of the sample decreases. For pure silica $L^{*}$ is 93.7. Addition of lignosulfonate causes a decrease in this parameter to $L^{*}=46.5$ for composite 7 and $L^{*}=47.3$ for composite 14 , the samples of the greatest weight contribution of lignosulfonate per 100 weight parts of hydrated and commercial silica, respectively. An important parameter in colorimetric study is $d E$, describing the total change in color. The value of $d E$ was found to increase systematically with increasing the ratio of lignosulfonate to silica matrix. This conclusion is supported by changes in the parameters $a^{*}$ and $b^{*}-$ describing changes in red and yellow components of the sample color. The results of colorimetric analysis of the final products obtained with the hydrated and commercial silicas are consistent with expectations and confirm the effectiveness of the method of synthesis in getting the target product.

Figure $7 \mathrm{a}$ presents the TG curves obtained for the precursors used, while Fig. $7 \mathrm{~b}$ - the curves recorded for the final silica/lignosulfonate composites.

Silica shows high thermal stability, the hydrated silica showed $6 \%$ mass loss, while the commercial silica (Aerosil ${ }^{\circledR} 200$ ) - 3\% mass loss in the temperature range studied. The mass loss of lignosulfonate was significant and reached $60 \%$ relative to the initial mass of the sample. The most significant second stage of mass loss of about $40 \%$ occurs in the range $150-400^{\circ} \mathrm{C}$. It is related initially to the endothermic process of water desorption and later to a complex thermal decomposition of the compound involving formation of new bonds as a result of cross-linking reactions ${ }^{27}$. The composites obtained with 20 weight parts of lignosulfonate per 100 weight parts of silica were found to show rather high thermal stability. The mass loss of composite 4 is $19 \%$, while that of composite 11 is $13 \%$, relative to the initial mass of the sample. The above presented results indicate that the composites obtained can be successful novel biomaterial applicable e.g. as polymer fillers.

Selected silica/lignosulfonate composites based on the commercial silica Aerosi ${ }^{\circledR} 200$ were subjected to porous structure characterization (Table 2) by the determination of the mean size and the total volume of pores as well as surface area BET.

The specific surface area BET determined for Ae$\operatorname{rosil}^{\circledR} 200$ is $249 \mathrm{~m}^{2} / \mathrm{g}$. With increasing admixture of lignosulfonate the surface area decreased to $167 \mathrm{~m}^{2} / \mathrm{g}$ for the composite of 50 weight parts of lignosulfonate per 100 weight parts of $\mathrm{SiO}_{2}$. For pure silica the total pore volume is $0.19 \mathrm{~cm}^{3} / \mathrm{g}$, while for the composites it varies from $0.12-0.14 \mathrm{~cm}^{3} / \mathrm{g}$ and decrease with increasing content of lignosulfonate. The mean pore diameter was $2.8 \mathrm{~nm}$ and was similar for all samples. The results characterizing the composites obtained suggest a possibility of their application as a natural adsorbent. The observed decrease in the surface area BET with increasing content of lignosulfonate in the composite does not have to deteriorate the adsorption properties. The large number of diverse functional groups present in the structure of this biopolymer can effectively chemically bind a number of organic compounds and heavy metal ions to the composite surface. Detailed studies of this problem are underway.

Table 2. Characteristics of the porous structure of Aerosil ${ }^{\circledR} 200$ and selected silica/lignosulfonate composites

\begin{tabular}{|l|c|c|c|}
\hline Composite No. & $\begin{array}{c}\text { BET surface area } \\
\left(\mathrm{m}^{2} / \mathrm{g}\right)\end{array}$ & Total volume of pores $\left(\mathrm{cm}^{3} / \mathrm{g}\right)$ & $\begin{array}{c}\text { Mean size of pores } \\
(\mathrm{nm})\end{array}$ \\
\hline Silica (Aerosil ${ }^{(8200)}$ & 249 & 0.19 & 2.81 \\
\hline 9 & 203 & 0.14 & 2.78 \\
\hline 11 & 190 & 0.13 & 2.78 \\
\hline 14 & 167 & 0.12 & 2.81 \\
\hline
\end{tabular}



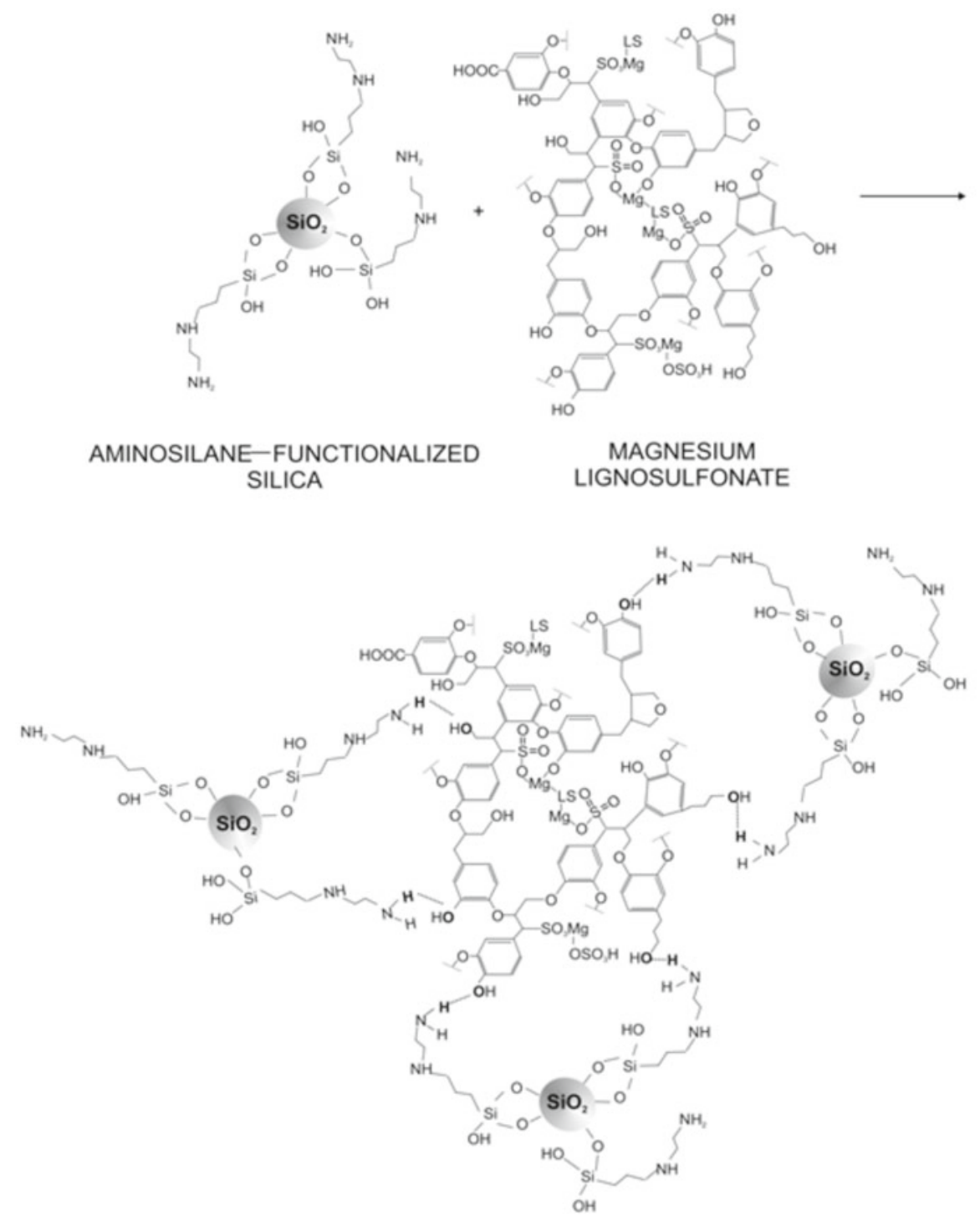

AMINOSILANE-FUNCTIONALIZED SILICA / MAGNESIUM LIGNOSULFONATE MATERIAL

Figure 5. The proposed formation mechanism of silica/magnesium lignosulfonate composites

\section{CONCLUSIONS}

New composites made of silica and magnesium lignosulfonate have been obtained. No significant differences in physicochemical properties were found between the composites based on hydrated silica and commercially available Aerosil ${ }^{\circledR} 200$. With an increasing content of lignosulfonate in the composites, their particles showed increasing tendencies for the formation of aggregates and agglomerates. The composites obtained were electrokinetically stable in almost all $\mathrm{pH}$ range analyzed. Relatively high values of their specific surface areas mean that they could be used as new composite-based sorbents of harmful organic substances and heavy metal ions. High thermal stability of silica/lignosulfonate composites is also promising for their application as polymer fillers. Further studies aiming at the verification of these conclusions are planned.

\section{ACKNOWLEDGEMENTS}

This work was supported by Poznan University of Technology research grant no. 32-375/2013-DS.

\section{LITERATURE CITED}

1. Jesionowski, T. \& Krysztafkiewicz, A. (2001). Influence of silane coupling agents on surface properties of precipitated silicas, Appl. Surf. Sci. 172, 18-32. DOI: 10.1016/S0169-4332(00)00828-X.

2. Jesionowski, T. (2002). Effect of surfactants on the size and morphology of the silica particles prepared by an emulsion technique, J. Mater. Sci. 37, 5275-5281. DOI: $10.1023 / \mathrm{A}: 1021064705690$.

3. Jesionowski, T. (2009). Preparation of spherical silica in emulsion system using the co-precipitation technique, Mater. Chem. Phys. 113, 839-849. DOI: 10.1016/j.matchemphys.2008.08.067.

4. Stöber, W., Fink, A. \& Bohn, E. (1968). Controlled growth of monodisperse silica spheres in the micron size range, $\mathrm{J}$. Colloid Interface Sci. 26, 62-69. DOI: 10.1016/0021-9797(68)90272-5.

5. Ibrahim, I.A.M., Zikry, A.A.F. \& Sharaf, M.A. (2010). Preparation of spherical silica nanoparticles: Stöber silica, J. Am. Sci. 6, 985-989. DOI: 10.1023/A:1026056716397.

6. Ouyang, X., Qiu, X. \& Chen, P. (2006). Physicochemical characterization of calcium lignosulfonate - a potentially useful water reducer, Colloids Surf. A: Physicochem. Eng. Aspects 282-283, 489-497. DOI: 10.1016/j.colsurfa.2005.12.020. 
(a)

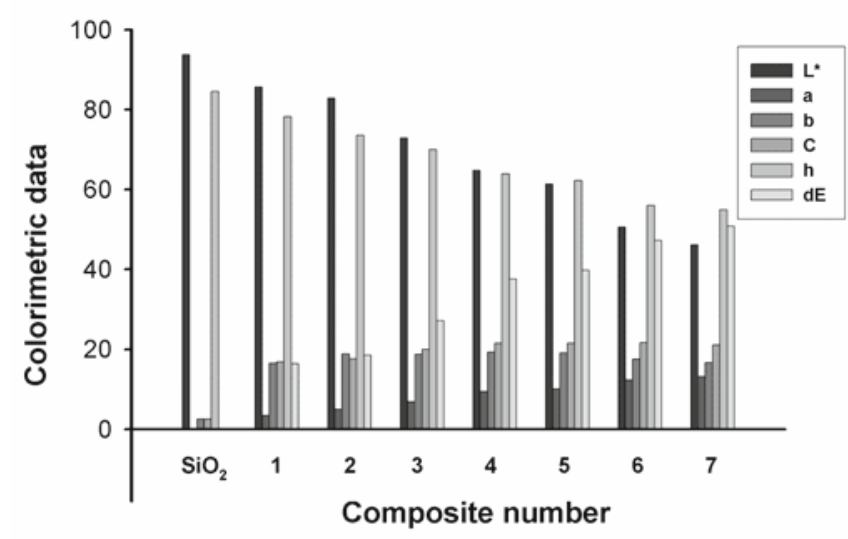

(b)

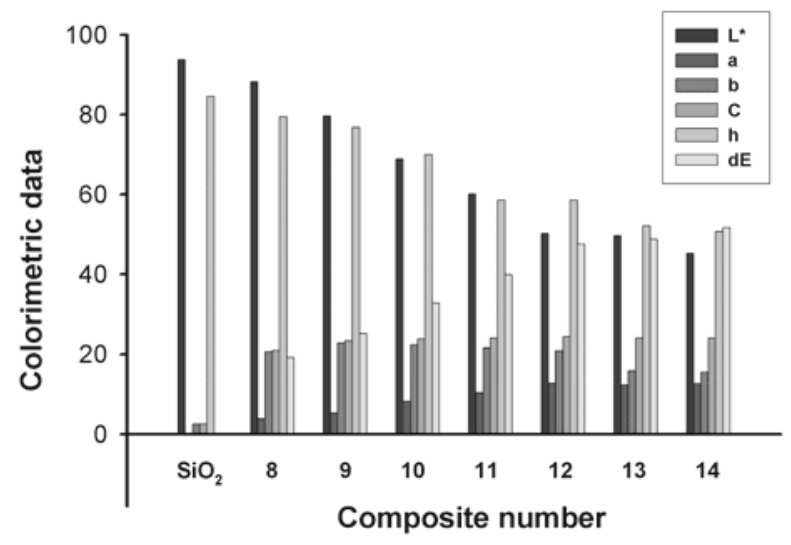

Figure 6. Colorimetric data of silica and silica/lignosulfonate composites obtained on the basis of (a) hydrated silica and (b) Aerosi ${ }^{\circledR} 200$

7. Telysheva, G., Dizhbite, T., Paegle, E., Shapatin, A. \& Demidov, I. (2001). Surface-active properties of hydrophobized derivatives of lignosulfonates: effect of structure of organosilicon modifier, J. Appl. Polym. Sci. 82, 1013-1020. DOI: 10.1002/app.1935.

8. Alonso, M.V., Oliet, M., Rodriguez, F., Astarloa, G. \& Echeverria, J.M. (2004). Use of a methylolated softwood ammonium lignosulfonate as partial substitute of phenol in resol resins manufacture, J. Appl. Polym. Sci. 94, 643-650. DOI: 10.1002/app.20887.

9. Chiwetelu, C.I., Hornof, V., Neale, G.H. \& George, A.E. (1994). Use of mixed surfactants to improve the transient interfacial tension behavior of heavy oil/alkaline systems, Can . J. Chem. Eng. 72, 534-540. DOI: 10.1002/cjce.5450720320.

10. Ansari, A., Pawlik, M. (2007). Floatability of chalcopyrite and molybdenite in the presence of lignosulfonates. Part I. Adsorption studies, Miner. Eng. 20, 600-608. DOI: 10.1016/j. mineng.2006.12.007.

11. Gargulak, J.D. \& Lebo, S.E. (2000). Commercial use of lignin-based materials, ACS Symp. Ser. 742, 304-320. DOI: 10.1021/bk-2000-0742.ch015.

12. Klapiszewski, Ł., Mąrawska, M. \& Jesionowski, T. (2012). Preparation and characterisation of hydrated silica/ lignin biocomposites, Physicochem. Probl. Miner. Process. 48, 463-473. DOI: 10.5277/ppmp120212.

13. Klapiszewski, Ł., Nowacka, M., Szwarc-Rzepka, K. \& Jesionowski, T. (2013). Advanced biocomposites based on silica and lignin precursors, Physicochem. Probl. Miner. Process. 49, 497-509. DOI: $10.5277 /$ ppmp130211.

14. Klapiszewski, Ł., Nowacka, M., Milczarek, G. \& Jesionowski, T. (2013). Physicochemical and electrokinetic properties (a)

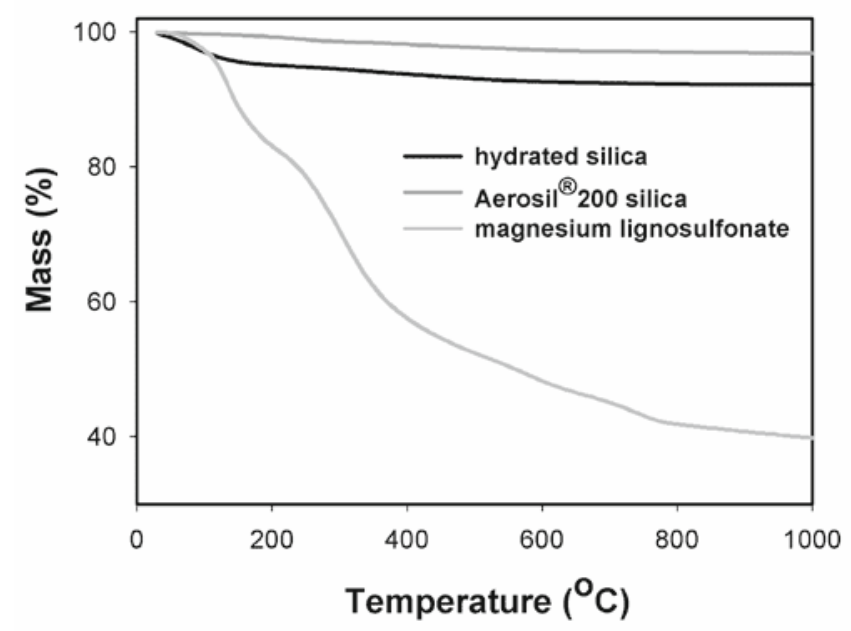

(b)

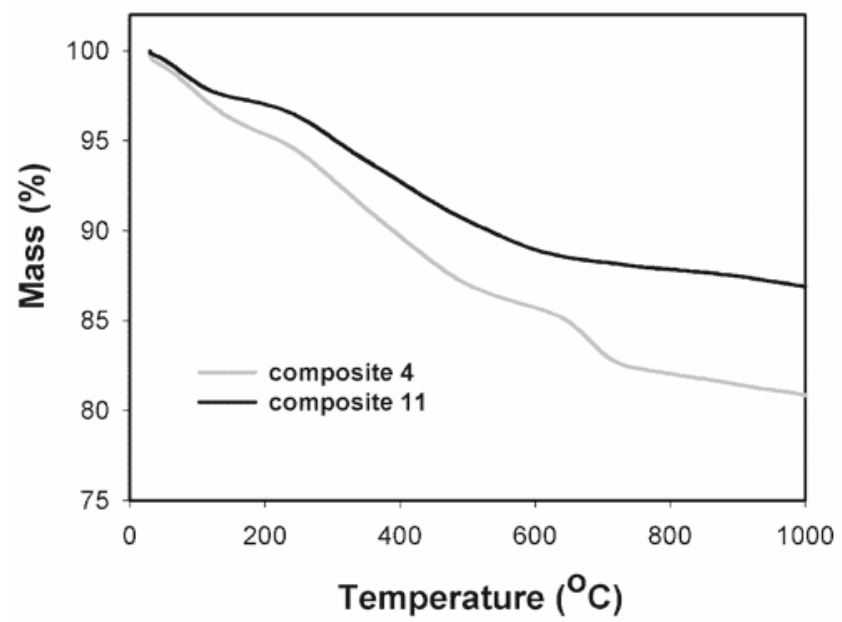

Figure 7. Thermal stability of silicas, magnesium lignosulfonate, and selected composites

of silica/lignin biocomposites, Carbohydrate Polym. 94, 345-355. DOI: 10.1016/j.carbpol.2013.01.058.

15. Prasetyo, E.N., Kudanga, T. \& Fischer, R. (2012). Enzymatic synthesis of lignin-siloxane hybrid functional polymers, Biotechnol. J. 7, 284-292. DOI: 10.1002/biot.201100106.

16. Qu, Y., Tian, Y. \& Zou, B. (2010). A novel mesoporous lignin/silica hybrid from rice husk produced by a sol-gel method, Bioresource Technol. 101, 8402-8405. DOI: 10.1016/j. biortech.2010.05.067.

17. Mishra, S.B., Mishra, A.K. \& Krause, R.W. (2009). Growth of silicon carbide nanorods from the hybrid of lignin and polysiloxane using sol-gel process and polymer blend technique, Mater. Lett. 63, 2449-2451. DOI: 10.1016/j.matlet.2009.08.029.

18. Gregorová, A., Košikovă, B. \& Moravčik, R. (2006). Stabilization effect of lignin in natural rubber-based composites, Polym. Degrad. Stabil. 91, 229-233. DOI: 10.1002/app.24530.

19. Kadla, J.F. \& Kubo, S. (2004). Lignin-based polymer blends: analysis of intermolecular interactions in lignin-synthetic polymer blends, Compos Part A: Appl. S. 35, 395-400. DOI: 10.1016/j.compositesa.2003.09.019.

20. Jesionowski, T. \& Krysztafkiewicz, A. (2000). Comparison of the techniques used to amorphous hydrated silicas, J. Non-Cryst. Solids 277, 45-57. DOI: 10.1016/S0022-3093(00)00299-4.

21. Yan, M., Yang, D., Deng, Y., Chen, P., Zhou, H. \& Qiu, $\mathrm{X}$. (2010). Influence of $\mathrm{pH}$ on the behavior lignosulfonate macromolecules in aqueous solution, Colloids Surf. A 371, 50-58. DOI: 10.1016/j.colsurfa.2010.08.062.

22. Myrvold, B.O. (2008). A new model for the structure of lignosulphonates part 1. Behavior in dilute solutions, Ind. Crops. Prod. 27, 214-219. DOI: 10.1016/j.indcrop.2007.07.010. 
23. Jesionowski, T., Żurawska, J., Krysztafkiewicz, A., Pokora, M., Waszak, D. \& Tylus, W. (2003). Physicochemical and morphological properties of hydrated silica precipitated following alkoxysilane surface modification, Appl. Surf. Sci. 205, 212-224. DOI: 10.1016/S0169-4332(02)01090-5.

24. Jesionowski, T., Pokora, M., Sobaszkiewicz, K. \& Pernak J. (2004). Preparation and characterization of functionalized precipitated silica SYLOID ${ }^{\circledR} 244$ using ionic liquids as modifiers, Surf. Interface Anal. 36, 1491-1496. DOI: 10.1002/sia.1927.

25. Szwarc-Rzepka, K., Marciniec, B., Jesionowski, T. (2013). Immobilization of multifunctional silsesquioxane cage on precipitated silica supports, Adsorption 19, 483-494. DOI: 10.1007/ s10450-013-9470-2.

26. Ye, D., Jiang, X., Xia, C., Liu, L. \& Zhang, H. (2012). Graft polymers of eucalyptus lignosulfonate calcium with acrylic acid: Synthesis and characterization, Carbohydr. Polym. 89, 876-882. DOI: 10.1016/j.carbpol.2012.04.024.

27. Lü, Q., He, Z., Zhang, J. \& Lin, Q. (2011). Preparation and properties of nitrogen-containing hollow carbon nanospheres by pyrolysis of polyaniline-lignosulfonate composites, J. Anal. Appl. Pyrol. 92, 152-157. DOI: 10.1016/j.jaap.2011.05.009. 